\title{
A STUDY OF THE RELIABILITY AND VALIDITY OF THE LEADER-MEMBER EXCHANGE (LMX) INSTRUMENT IN ARABIC
}

\author{
AreejAlshamasi ${ }^{1}$ and NahlaAljojo ${ }^{2}$ \\ ${ }^{1}$ Faculty of Economics and Administration, Public Administration Department, King \\ Abdulaziz University, P.O. Box 9417, Jeddah, 21413, Saudi Arabia \\ ${ }^{2}$ Faculty of Computing and Information Technology, Information Systems Department, \\ King Abdulaziz University, P.O. Box 132139, Jeddah, 21382, Saudi Arabia
}

\begin{abstract}
There are difficulties associated with the use of English language versions of cohesive psychometric instruments tomeasure Leader-Member Exchange (LMX) in a non-English speaking business environment. These instruments are generally composed in English and are most suited to Western culture. Use of these instruments in an alternative language can lead to problems in terms of translation and culture. For example, there are often linguisticvariations in a literal translation of questions or items, which can lead to subtle orperhaps significantlyaltered meanings in the translated instruments, an issue that may jeopardise the validity and reliabilityofmeasurements.
\end{abstract}

This articlediscusses research into the formulation of an Arabic version of the Leader-Member Exchange (LMX) instrument. A literal translation of the LMX was applied to 433 employees at the King AbdulazizUniversity (KAU) and the outcome generated a greater degree of internal validity to thatgenerated by the English language versions.

\section{KEYWORDS}

Leader-Member Exchange (LMX), psychometric, Leader-follower,translation protocol, validity, reliability, factor analysis

\section{INTRODUCTION}

Northo use (2007) argues that the majority of leadership theories approach leadership from the perspective of leaders (e.g. trait approach, skills approach, and style approach) or followers as well as situations (e.g. situational leadership, contingency theory and path-goal theory). Effective leadership is not only dependent on the traits or attributes of leaders, followers and situations as it extends past the specific attributes of leaders to the nature of the relationship that is forged between leaders and followers, a relationship that determines the quality of exchange. Thus, it is important that leaders focus primarily on the interactions that improve the organisational collective effort (Hackman \&Wageman, 2005; Yukl, 2008). The most suitable way of demonstrating the value of this is to conceptualise leadership as a process that is primarily driven by the manner in which leaders and followersinteract (e.g. Sparrowe, Liden, Wayne\&Karimer, 2001; Graen\& Uh-Bien, 1991, 1995; Popper, 2004; Yukl, 2010). Using this approach, the interactive relationship between the leader-member (dyad), a two-way relationship, is the basic premise and unit of analysis of LMX (Dansereau, Graen, \&Haga, 1975; Graen\&Cashman, 1975; Truckenbrodt, 2000). 
For contemporary organisations, the quality of the relationship between leaders and followers is regarded as one of the most fundamental considerations for a business that aims to forge a tenable and stable organisational culture (Wang, Law, Hackett, Wang \& Chen, 2005). The impact of the quality of leader-follower relationships in the workplace has been subject to analysis by many theorists and academic works have generated valuable findings on the value of the leaderfollower relationship in the field of organisational psychology (e.g. Gomez \& Rosen, 2001; Sparrowe et al., 2001; Graen\& Uh-Bien, 1995; Hollander, 1992a; 1992b; Bass \&Avolio, 1990). The significance of a robust leader- follower relationship is also reinforced by the fact that it can increase employee morale and encourage followers to demonstrate more positive behaviours (Sparrowe et al., 2001).

LMX is a strong descriptive theory that analyses work units from the perspective of role theory (Graen, 1976; Katz \& Kahn, 1978; Graen\&Scandura, 1987) and social exchange theory (Blau,1964), using these frameworks as explanatory mechanisms for the development and maintenance of dyadic leader-follower relationships. Uhl-Bien, Maslyn and Ospina (2012) substantiated the theory that the quality of leaders' interactions with their followerscan be correlated with several positive effects. Detailed analysis on LMX has also substantiated theories on the link between LMX and a host of attitudinal and behavioural impacts(e.g. Gerstner \& Day, 1997; Ilies, Nahrgang\&Morgeson, 2007; Dulebohn, Bommer, Liden, Brouer\& Ferris, 2011).

The present study built on LMX from a multidimensional perspective and employed the four dimensions for measurement of LMX introduced by LidenandMaslyn (1998), namely affect, loyalty, contribution and professional respect (see figure 1).

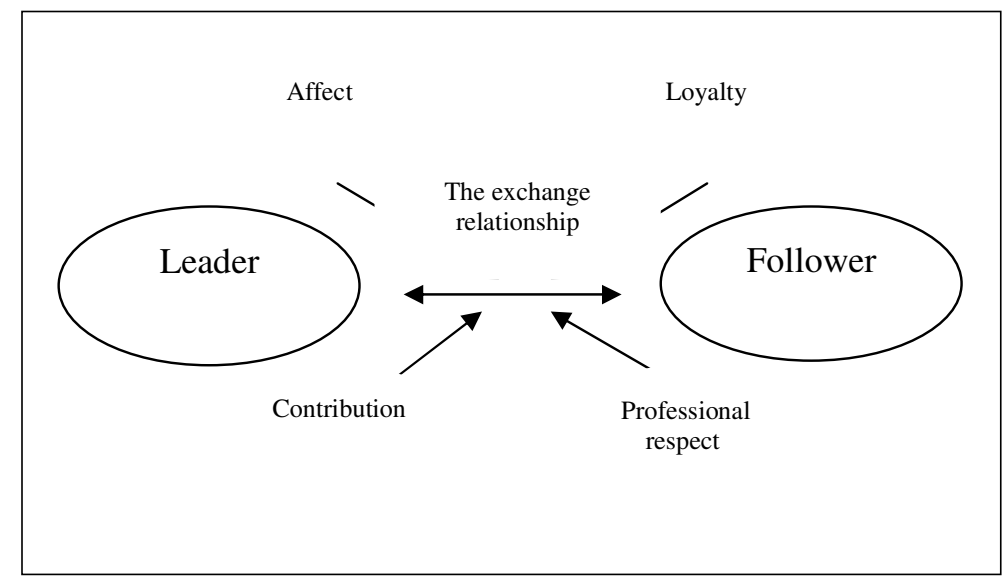

Figure 1: Concept of the exchange relationship based on the four dimensions of the LMX approach as proposed by Liden and Maslyn (1998)

This article expands upon existing research into the translation of research instruments bypresenting a procedure used for the translation and cultural adaptation of an Arabic version of the Leader-Member Exchange (LMX) instrument.The process discussed offers advice as well as a procedural framework based on which researchers can perform a cross cultural adaptation of instruments. This Arabic version of the LMXwas employed in a Saudi work environment that comprised 433employees at King Abdul-Aziz University (KAU) in Saudi Arabia, Jeddah. This study has been performed for two main reasons.Firstly, rapid organisational development in Saudi organisations have led tosignificant changes in the structure of the university and its various regulations and policies. Secondly, the majority of LMX analyses have been performed by western scholars and the present researcher wished to determine the feasibly of the LMX 
approach when used in a Saudi cultural context. The process discussed also expands upon validating instruments by incorporating items such as content validity and factor analysis in terms of the translationwith particular reference to Arabic societies; however, this procedure is highly adaptable and can easily be applied to a variety of cultures and languages.

\section{LEADERSHIP AS A PROCESS: THE LEADER-MEMBER EXCHANGE (LMX) THEORY}

LMX theory posits that exchanges (i.e, work and social interactions) often occur between managers and their employees. Managerscultivate relationships of varying levels of quality with their employees on the basis of these exchanges. Employees that have a positive relationship with managers are oftentreated more favourablythan those who have low quality relationships with their superiors. For instance, employees that develop high quality relationships with managers may benefit from more communication, more favourable work assignments, a greater degree of emotional support and easier access to a diverse range of company resources(Dienesch\&Liden, 1986; Graen\&Scandura, 1987; Wayne, Shore \&Liden, 1997).

LMX theory is easy to comprehend in light of the leadership making model promulgated by Graen and Uhl-Bien (1991, 1995). This model focuses on the improvement of leadership processesby forging more high quality leadership relationships (leadership making). Under this approach, the focus is not on how managers discriminate between their followers (classify them as "in-group" and "out-group" team members) but instead on how well they collaborate with individual employees and develop strong personal relationships (Graen and Uhl-Bien, 1995). This approach also requires employees to be informed of the LMX process and requires managers to make preliminary offers to cultivate LMX partnerships with individual employees. Thus, the LMX process is often regarded as more impartial as all employees are treated equitably by leaders (Graen\&Uhl-Bien, 1995; Scandura, 1999).

Northouse (2007) makes the distinction between early and later analyses of LMX. He asserts that some of the earliest works on LMX concentrated primarily on the vertical linkage forged by leaders with all of their subordinates. The quality of this linkage then determined which of the followers belonged to the "in-group" and which belonged to the "out-group" (e.g. Dansereau et al., 1975; Graen, \&Scandura, 1987). Those who formed part of the in-group are generally reliable followers who have forged a robust relationship with the leader; furthermore, in-group members often benefit from additional remuneration or special privileges (Northouse, 2007; Graen\&UhlBien, 1991; 1995). Those who do not form part of the in-group naturally form part of the outgroup. These followers do not receive much attention from the leader and are unlikely to receive any of the extra benefits that are distributed amongst the team. In effect, the relationship between the leader and their followers is based on formal authority interactions (Northouse, 2007; Graen\&Uhl-Bien, 1991; 1995).

Subsequent LMX investigations analysed how the quality of LMX had a beneficial impact on leaders, followers and the organisation as a whole (e.g. Graen\&Uhl-Bien, 1995; Liden, Wayn\& Stilwell, 1993). GraenandUhil-Bien $(1991 ; 1995)$ were the first to propose the notion of leadership making as they analysed how interaction between leaders and followers played a key role in the leadership making process. Leadership making theory alsoposits that a leader must participate in high-quality exchanges with all subordinates as opposed to just a select few (Graen\& Uh-Bien, 1995; Northouse, 2007). This perspective was formulated in response to the favouritism demonstrated by many leaders who subconsciously categorised their employees as "in-group" and "out-group" members (e.g. Harter \&Evanecky, 2002; Scandura, 1999). Challenges to the "in-group" and "out-group" differentiation system highlight the importance of 
identifying situation-specific factors that may facilitate leaders in treating all followers more equitably.

\section{LEADER-MEMber EXCHANGE (LMX) APPROACH: THE MULTIDIMENSIONAL CONCEPT OF LMX}

The multidimensional aspect of LMX enables the use of LMX quality as a cohesive measurementand as independent measurements based on four dimensions to predict individual outcomes (Liden\&Maslyn,1998; Maslyn\&Uhl-Bien, 2001).

Bhal, Gulati and Ansari (2009) claim that the majority of early studies treated LMX as a onedimensional concept in forecasting employee-based impacts using LMX-7 as formulated by Graen and Uhl-Bien (1995).Using this one-dimensional measurement, the exchange relationship focuses only on thetasks at hand and places limited emphasis on the analysis and evaluation of social interactions (Bhal et al., 2009). Graen and Uhl-Bien (1995, pp. 237-238) claim that the development of LMX was driven primarily by the attributes of the working relationship as opposed to the interpersonal relationship and the level of trust or compassion that is forged between individuals is based solely on each person'sestimation of the other's professional competence and behaviour. Conversely, multidimensional LMX incorporates the liking-based dimensions of personal relationships, including affect, loyalty, and respect, as well as work-based dimensions, including contribution (Dienesch\&Liden, 1986; Liden\&Maslyn, 1998). As a result,DieneschandLiden (1986) and LidenandMaslyn (1998) dispelled the notion that LMX is a one-dimensional concept and insteadproposed a multidimensional conceptualisation as it offers a more cohesive overview of the LMX quality characteristics. In effect, this approach offers a moreunified perspective on LMX from a conceptual standpoint.

In agreement with Liden and Maslyn's (1998) conceptualisation of LMX, this approach centres onthe fluctuating levels of "currencies of exchange": being fond of someone (labelled affect), loyalty to one other (labelled loyalty), work-based behaviours (labelled contribution) and professional respect (respect of leaders' capabilities). All four dimensions of LMX are relevant to the present study and will be analysed accordingly. Liden and Maslyn's (1998) multidimensional LMX concept can be described as follows:

(1) Affect - This dimension refers to the fondness of team members for one another and is based solely on personal connections as opposed to respect that is cultivated on the basis of one's professional competence and achievements (social currency).

(2) Loyalty - This is demonstrated by followers and leaders when they vocally support one another's endeavours. Followers demonstrate their loyalty to the leader when they adopt the leader's visions and goals as their own (social currency).

(3) Contribution - This refers to the amount of work performed by employees in pursuit of a specific goal or outcome set by the leader (work-related currency).

(4) Professional respect - This refers to how much respect the members of the dyad have towards their colleagues as well as the internal and external reputation of each member based on their professional competence and area of expertise (social currency).

The authors posit that an exchange between leaders and members may involve one or more of these dimensions. Therefore, a "contribution-dominated" exchange (work-related currency) will probably feature extensive interaction in relation to work-based tasks while an "affectdominated" exchange (social currency) will probably feature off-the-job, affective and interpersonal interactions (Bhal et al., 2009; Maslyn\&Uhl-Bien, 2001). Thus, varying currency levels of LMX will generate different predictions in terms of work-based outcomes. 
In addition, Maslyn and Uhl-Bien (2001) suggest the likelihood of variance in the weight or significance of all four dimensionsfor different individuals. In effect, an individual may have different motivations for forging a high quality LMX relationship. For instance, an exchange of high quality that is based primarily on contribution may be generated by a leader and follower who often collaborate on work tasks outside of regular work hours while an exchange of high quality that is based primarily on affect may be generated by a leader and subordinate that often talk about non-work related matters during business hours (Maslyn\&Uhl-Bien, 2001).

\section{Methodology}

\subsection{Measurements Processes}

LMX is measured using a 12-item LMX-multidimensional scale (Liden\&Maslyn, 1998) comprising four subscales ( 3 items per scale) of LMX dimensions. The LMX-multidimensional composite measure was first promulgated by Liden\&Maslyn (1998) and enables theassessment of LMX as a whole along with its relevant dimensions. This measure was formulated to capture the affect, loyalty,contribution, and professional respect dimensions of LMX in order to assess the quality of LMX from a rather broad perspective. A 5-item Likert-type scale ranging from $1=$ Strongly disagree to $5=$ Strongly agree was employed. Internal consistency reliabilities were found to be adequate in terms of the affect, loyalty and professional respect scales; however, they were unacceptable in terms of the contribution scale in a study byLiden and Maslyn (1998). The coefficient alphas were $.90,78, .60$ and .92 respectively for affect, loyalty, contribution and professional respect based on a single sample (students), and $.90, .74, .57$, and .89 respectively for affect, loyalty, contribution, and professional respect for a sample group composed of organisational employees.

In terms of reliability in the LMX-Contribution dimension, subsequent studiesoffered substantiating evidence that the contribution dimension can indeed be regarded as a valid dimension of LMX. Liden and Maslyn's (1998) scale has been subject to evaluation in earlier worksand typically demonstrates positive psychometric characteristics. For instance, Maslyn and Uhl-Bien (2001) measured a high level of internal consistency in terms of theentire scale $(\alpha=.92)$. In their study, the internal consistency for each dimension was calculated as: Affect, $\alpha=.86$, Loyalty, $\alpha=.80$, Contribution, $\alpha=.66$ and Professional Respect, $\alpha=.84$. Furthermore,Schyns and Wolfram (2008) discovered that the reliability (Cronbach's alphas) for the LMX dimensions was as follows: $\alpha=.93, \alpha=.89, \alpha=.80$ and $\alpha=.62$ for affect, loyalty, contribution, and professional respect respectively. The value for LMX-contribution in this study was also regarded as acceptable. In light of these findings, the LMX-contribution reported good reliability values in the present study with $\alpha=.754$ in the pilot test and $\alpha=.736$ in the main study.

\subsection{Pre-Testing the Questionnaire (The Arabic version of the LMX scale)}

The questionnaire (LMX scale) was pre-tested prior to the performance of the main study in order to identify any weaknesses in the design and structure of the questionnaire. The following section discusses the actions that were taken to ensure the validity of the questionnaire (The Arabic version of LMX scale). There were two stages involved in implementing these measures:

\subsubsection{First step: LMX scale translation procedures}

LMX questions were originally composed in English. As the empirical section of this study was performed in an Arabic context, the LMX scale was translated from English into Arabic. The translation was made by an accomplished English-Arabic translator who ensured that the correct meaning of each question was retained and reflected in the Arabic version of the LMX scale. This 
was an essential step in the performance of the present study as many of the participants were unfamiliar with the English language. To ensure measurement equivalence and precision, the translated version was translated back into English (Brislin, Lonner\& Thorndike, 1973; Brislin, 1980; Cohen \& Cohen, 1983) by a different English-Arabic specialist translator in order to ensure that the meaning of the translated version fully reflected the intended meaning of the original. Next, the Arabic version was assessed by a panel of 8 academic staff from King Abdul Aziz University who offered recommendations as to how some of the scale questions could be simplified. As a result, modifications were made to some of the translated items in order to increase clarity. The Arabic version of the LMX scale was then subject to testing through the performance of a pilot study, tests which determined the validity of the instrument and its suitability for the collection of data necessary to perform the main study. The outcome of the pilot tests will now be discussed.

\subsubsection{Second step: Pilot study}

A pilot study was performed in order to determine the validity of the data collection methods. More specifically, it was important to judge the validity and reliability of the LMX scale in the Arabic version of the survey. The pilot study was performed on the attitudes of employees toward LMX and involved 53 Saudi employees from a number of different public sector organisations in Jeddah, Saudi Arabia. Of the 100 employee questionnaires sent out, 53 completed surveys were returned. Thus, the response rate for the pilot study was 53\%, which is an acceptable rate for statistical testing that will be discussed in the next section.

All academic research surveys must be tested prior to the beginning of a primary study so that the clarity and lay-out of the questions can be assessed as well as the overall structure of the survey. This strategy is also effective in lowering the likelihood of participants having difficulty responding to questions and also enables the researcher to evaluate the validity and the reliability of the data collected using the instrument. The pilot test was an essential part of the present study and was performed prior to the launch of the main study. The pilot test provided an insight into the time required to answer the survey questions and the ease with which translated questions could be understood; in addition, the pilot study highlighted specific questions that were a little unclear and these findings were used to modify the instrument before the final version was administered.

\subsubsection{Validity and reliability of the questionnaire (The Arabic version of the LMX scale) in the pilot study}

The pilot study was performed to determine the validity and reliability of the Arabic translation of LMX scales. To achieve this, factor analyses and the Cronbach's Alpha reliability test (Cronbach, 1984) were conducted. Firstly, in order to test the factorial validity of the translated scale, confirmatory factor analysis was performed using a maximum likelihood method (CFA) in order to ensure that LMX scale items were loaded on the same factors that had been highlighted in previous studies. Factor analysis identifies variables that appearto form meaningful clusters (Field, 2009). In order to perform factor analysis, specific criteria must be metso that factor analysis can be successfully performed. For instance, it is vital thatinterval scales are used to measure variables (Hair, Anderson \&Tatham, 1998). The 5-point Likert scale that was incorporated into the design of the survey fulfilled this requirement. Following the suggestions of Tabachnick and Fidell (2007), the present study chose to validate the factors that have Eigen values higher than 1 and to omit items with a loading of 0.3 or lower. This action was taken to ensure that the findings generated by factor analysis were as meaningful as possible. In accordance with Tabachnick and Fidell (2007), an Eigen value of at least 1 was calculated for each domain and computed values of at least 0.3 were obtained. The rotated scale of LMX implies that items were loaded on four factors and each of the three items was loaded on its respective domain. 
In order to determine the reliability of the LMX scale, the test of inter-item consistency reliability, Cronbach's coefficient alpha ( $\alpha$ ), was applied (Cronbach, 1984). Bell (2005) believes that reliability refers to how consistently a test generates analogous results when performed under the exact same conditions multiple times. A reliability value falls anywhere between 0 and 1 with values closer to 1 indicating a higher degree of reliability. In this case, a reliability value of at least 0.7 was required (Hair et al., 1998; Hair, Tatham, \& Anderson, 2002). Nonetheless, a value of 0.6 is obtained and this is deemed high enough to be considered acceptable (Nunnally\& Bernstein, 1994). Thus, in this case, a value of at least 0.6 alpha $(\alpha)$ is regarded as acceptable in evaluating the reliability of the scales. Factor analysis results and the internal consistency of the LMX scale (pilot test) were computed using SPSS v.18.0. The results are presented in the following section.

-Factorial validity and reliability results for the Arabic version of the LMX scale in the pilot test

As was expected, the LMX quality scale items were related to at least one factor in terms of the four dimensions- affect, loyalty, contribution and professional respect. LMX items were intentionally extracted on four factors in accordance with the method used byLiden and Myslen (1998). The LMX scale was rotated through the use of confirmatory factor analysis with Varimax rotation and the items were extracted on 4 factors. According toJoreskog and Sorbom (1989), LMX multiple dimensions are discernible when confirmatory factor analysis is used to force factors. All three items were loaded on individual factors. The loading range of LMX-Affect items fell between .720 and .891 with Eigen values greater than 1. The loading range of LMXLoyalty items fell between .917 and .960 with Eigen values greater than 1 . The loading range of LMX-Contribution items fell between .312 and .864 with Eigen values greater than 1. Lastly, the loading range of LMX-Professional respect items fell between .839 and .955 with Eigen values greater than 1. The outcome of the reliability tests performed using Cron bach's alpha coefficient is displayed in the table below along with internal consistency reliability estimates which can be considered good according to Hair et al. $(1998 ; 2002)$.

Table 1: Factorial validity and reliability results in the pilot test

\begin{tabular}{|c|c|c|c|c|c|}
\hline $\mathbf{N}$ & Scale & $\begin{array}{c}\text { Item } \\
\text { s }\end{array}$ & $\begin{array}{l}\text { Factor } \\
\text { (s) }\end{array}$ & $\begin{array}{c}\text { Factor (s) } \\
\text { descriptions }\end{array}$ & Cronbach's Alpha \\
\hline \multirow{5}{*}{53} & \multirow{4}{*}{$\begin{array}{l}\text { LMX } \\
\text { quality }\end{array}$} & $1-3$ & \multirow{4}{*}{4} & Affect & $\alpha=.853$ \\
\hline & & $4-6$ & & Loyalty & $\alpha=.936$ \\
\hline & & $7-9$ & & Contribution & $\alpha=.754$ \\
\hline & & $\begin{array}{l}10- \\
12\end{array}$ & & $\begin{array}{l}\text { Professional } \\
\text { respect }\end{array}$ & $\alpha=.897$ \\
\hline & $\begin{array}{l}\text { Employabilit } \\
\text { y orientation }\end{array}$ & $1-7$ & 1 & $\begin{array}{c}\text { Positive attitudes } \\
\text { towards } \\
\text { developing skills } \\
\text { to perform new } \\
\text { tasks }\end{array}$ & $\alpha=.627$ \\
\hline
\end{tabular}




\subsection{Main Data Collection}

\subsubsection{Response rate}

A total of 433 valid employee questionnaires were collected from KAU departments out of the 500 questionnaires sent. Thus, this survey has an extremely favourable response rate of $87 \%$. Tsui, Ashford, St. Clair and Xin (1995) also reported excellent response rates of 90\% and 95\% for their two samples. The authors implied that different response rates can be justified based on the unique context in which the study was performed. In terms of the present study, an excellent response rate has been achieved for three specific reasons. Firstly, the researcher was already a member of KAU and thusfound it easier to secure access to the necessary research data. Secondly, the researcher adhered to all ethical protocol in completing the study. Finally, the researcher benefitted from the help of a KAU assistantand from the cooperation ofparticipants in every university department when circulating the questionnaires. These factors had a positive impact on the overall efficiency with which the survey was conducted. Thefollowing sectiondiscusses thedemographical attributesof the participants.

\subsubsection{Participants'Demographic Data}

The table below (Table 2) illustrates the demographical data for the participants. Based on this information, it is clear that most of the respondents were employees at the university. In terms of age, $37.6 \%$ of the respondents were between 20 and 29 years old whereas only 0.9 were 60 years or more. Furthermore, of those questioned, a total of 55.4\% had Bachelor's degrees whereasonly 9.7\% had achieved Master's degrees. In addition, the proportion of participants with less than 5 years' experience was $43.6 \%$ whereas $9.2 \%$ of the sample had between 15 and 20 years'experience. Finally, those with administration jobs accounted for $79.7 \%$ of the sample groupand the majority of those who participated in the survey were women.

Table 2: Demographic data for the participants (KAU employees)

\begin{tabular}{|c|c|c|c|}
\hline \multicolumn{2}{|c|}{ Demographic features } & \multicolumn{2}{c|}{ Employees } \\
\cline { 2 - 4 } & Between 20 and 30 & 163 & 37.6 \\
\cline { 2 - 4 } & Between 30 and 40 & 153 & 35.3 \\
\cline { 2 - 4 } Age & Between 40 and 50 & 83 & 19.2 \\
\cline { 2 - 4 } & Between 50 and 60 & 30 & 6.9 \\
\cline { 2 - 4 } & Above 60 & 4 & .9 \\
\hline \multirow{5}{*}{ Level of education } & Total & 433 & 100.0 \\
\cline { 2 - 4 } & $\begin{array}{c}\text { Less Than } \\
\text { Bachelor's }\end{array}$ & 82 & 18.9 \\
\cline { 2 - 4 } & Bachelor's & 240 & 55.4 \\
\cline { 2 - 4 } & Master's & 42 & 9.7 \\
\cline { 2 - 4 } & PhD & 69 & 15.9 \\
\hline
\end{tabular}


International Journal of Computer Science \& Information Technology (IJCSIT) Vol 8, No 1, February 2016

\begin{tabular}{|c|c|c|c|}
\hline \multirow{4}{*}{$\begin{array}{c}\text { Years of } \\
\text { experiences }\end{array}$} & Total & 433 & 100.0 \\
\hline \multirow{4}{*}{\begin{tabular}{c} 
Less than 5 \\
\cline { 2 - 3 }
\end{tabular}} & Between 5 and 10 & 189 & 43.6 \\
\cline { 2 - 4 } & Between 10 and 15 & 47 & 102 \\
\cline { 2 - 4 } & Metween 15 and 20 & 40 & 9.2 \\
\cline { 2 - 4 } & More than 20 & 55 & 12.7 \\
\hline \multirow{4}{*}{ Type of job } & Administrator & 433 & 100.0 \\
\cline { 2 - 4 } & Academic & 88 & 79.7 \\
\cline { 2 - 4 } & Total & 433 & 100.0 \\
\hline \multirow{4}{*}{ Gender } & Female & 363 & 83.8 \\
\cline { 2 - 4 } & Male & 70 & 16.2 \\
\cline { 2 - 4 } & Total & 433 & 100.0 \\
\hline
\end{tabular}

\section{RESULTS}

\subsection{Construct validity and reliability analysis for the main data}

The primary data was subject to confirmatory factor analysis and Cronbach's alpha ('the reliability coefficient') as these tests yielded significant results in the pilot study when applied to a smaller sample group.A larger sample size was used to generate the main findings, which should have a positive effect on the validity of these methods and their ability to produce more reliable results. The outcome of factorial validity as part of the main study has been tested usingTabachnick and Fidell's (2007) method and Eigen values that exceed 1 were obtained. The computed values for all domains were also deemed acceptable as they were equal to or greater than 0.3. Furthermore, Cronbach's alpha generated values of 0.6 and above and can thus be considered acceptable according to Nunnally and Bernstein's criteria (1994). These results are presented in section 5.3.

- Factor analysis and reliability test results for the main data

In order to determine factorial validity, all LMX scale items were subject to factor analysis based on the maximum likelihood method for the purposes of extraction. The LMX scale was rotated using Varimax rotation and all items were extracted based on four factors. Thus, it was discovered that the LMX scale could be linked to one or more factor in terms of the four key dimensions: affect, loyalty, contribution and professional respect.

The factor analysis results were then substantiated by evaluating the reliability of each scale.The internal consistency reliability results generated by Cronbach's alpha $(\alpha)$ were above .7 for LMX dimensions. These reliability values can be regarded as acceptable based on the criteria delineated 
International Journal of Computer Science \& Information Technology (IJCSIT) Vol 8, No 1, February 2016

by Hair et al. (1998; 2002). Thus, the predicted reliability values were deemed favourable for the entire LMX scale (see table 3).

Table 3: Factor analysis and reliability test results for the main data (KAU employees) $(\mathrm{N}=433)$

\begin{tabular}{|c|c|c|c|c|c|c|c|}
\hline \multicolumn{8}{|c|}{ 3-LMX (Rotated) } \\
\hline \multirow{3}{*}{$\begin{array}{l}\text { Scale } \\
\text { items }\end{array}$} & \multicolumn{5}{|c|}{ Factorial statistics } & \multirow[b]{2}{*}{ Specified factor(s) } & \multirow[b]{2}{*}{ Cronbach's Alph } \\
\hline & \multicolumn{4}{|c|}{ Loadings } & $\begin{array}{l}\text { Eigen } \\
\text { values }\end{array}$ & & \\
\hline & 1 & 2 & 3 & 4 & \multirow{4}{*}{5.047} & \multirow{4}{*}{ LMX-Affect } & \multirow{4}{*}{$\alpha=.881$} \\
\hline 1 & $\begin{array}{c}.84 \\
0 \\
\end{array}$ & & & & & & \\
\hline 2 & $\begin{array}{c}.92 \\
6 \\
\end{array}$ & & & & & & \\
\hline 3 & $\begin{array}{c}.80 \\
9 \\
\end{array}$ & & & & & & \\
\hline 4 & & .863 & & & \multirow{3}{*}{4.385} & \multirow{3}{*}{ LMX-Loyalty } & \multirow{3}{*}{$a=.909$} \\
\hline 5 & & .944 & & & & & \\
\hline 6 & & .822 & & & & & \\
\hline 7 & & & & .705 & \multirow{3}{*}{2.544} & \multirow{3}{*}{ LMX-Contribution } & \multirow{3}{*}{$a=.736$} \\
\hline 8 & & & & .759 & & & \\
\hline 9 & & & & .606 & & & \\
\hline 10 & & & $\begin{array}{c}.90 \\
1\end{array}$ & & \multirow{3}{*}{4.808} & \multirow{3}{*}{$\begin{array}{l}\text { LMX-Profes sional } \\
\text { respect }\end{array}$} & \multirow{3}{*}{$\alpha=.930$} \\
\hline 11 & & & $\begin{array}{c}.94 \\
7 \\
\end{array}$ & & & & \\
\hline 12 & & & $\begin{array}{c}.87 \\
0 \\
\end{array}$ & & & & \\
\hline \multicolumn{8}{|c|}{ Employability orientation } \\
\hline \multirow{2}{*}{ Scale items } & \multicolumn{5}{|c|}{ Factorial statistics } & \multirow{2}{*}{ Specified factor(s) } & \multirow{2}{*}{ Cronbach's Alphs } \\
\hline & \multicolumn{3}{|c|}{ Loadings } & \multicolumn{2}{|c|}{ Eigen value } & & \\
\hline 1 & \multicolumn{3}{|c|}{.596} & \multirow{7}{*}{\multicolumn{2}{|c|}{1.881}} & \multirow{7}{*}{$\begin{array}{l}\text { The items were } \\
\text { perfectly loaded on } 1 \\
\text { factor (Employability } \\
\text { orientation) }\end{array}$} & \multirow{7}{*}{$a=620$} \\
\hline 2 & \multicolumn{3}{|c|}{.510} & & & & \\
\hline 3 & & .33 & & & & & \\
\hline 4 & \multicolumn{3}{|c|}{.585} & & & & \\
\hline 5 & \multicolumn{3}{|c|}{.700} & & & & \\
\hline 6 & & .64 & & & & & \\
\hline 7 & & .33 & & & & & \\
\hline
\end{tabular}

\subsection{Ranking Analysis of Likert-Type Scale: The Findings of LMX Quality Assessment from the Perspective ofKAU Employees}

Ranking analysis was applied to KAU employees $(\mathrm{N}=433)$ for the purpose of rating LMX quality from the perspective of employees. The attitudes for each dimension and its items and for the LMX scale as a whole are displayed in the following table: 
International Journal of Computer Science \& Information Technology (IJCSIT) Vol 8, No 1, February 2016

Table 4: Ranking analysis of LMX quality $(\mathrm{N}=433)$

\begin{tabular}{|c|c|c|c|c|c|c|c|c|}
\hline Statement & $\begin{array}{l}\begin{array}{l}\text { Stron } \\
\text { gly } \\
\text { Disa } \\
\text { gree }\end{array} \\
\%\end{array}$ & $\begin{array}{c}\begin{array}{c}\text { Disag } \\
\text { ree }\end{array} \\
\%\end{array}$ & $\begin{array}{c}\text { Neutr } \\
\text { al }\end{array}$ & $\begin{array}{c}\text { Agre } \\
\mathrm{e} \\
\%\end{array}$ & $\begin{array}{l}\text { Stron } \\
\text { gly } \\
\text { Agre } \\
\text { e } \\
\%\end{array}$ & $\begin{array}{l}\text { Weigh } \\
\text { ted } \\
\text { mean }\end{array}$ & $\mathrm{CV}$ & Attitude \\
\hline $\begin{array}{l}\text { 1. I like my supervisor } \\
\text { very much as a person }\end{array}$ & 2.1 & 2.1 & 7.6 & 41.1 & 47.1 & 4.29 & 20.0 & $\begin{array}{l}\text { Strongl } \\
\text { y Agree }\end{array}$ \\
\hline $\begin{array}{l}\text { 2. My supervisor is the } \\
\text { kind of person one would } \\
\text { like to have as a friend. }\end{array}$ & 3.0 & 3.5 & 16.6 & 34.2 & 42.7 & 4.10 & 24.3 & Agree \\
\hline $\begin{array}{l}\text { 3. My supervisor is a lot of } \\
\text { fun to work with }\end{array}$ & 4.6 & 9.0 & 20.3 & 30.9 & 35.1 & 3.83 & 29.8 & Agree \\
\hline Affect & 3.2 & 4.8 & 14.9 & 35.4 & 41.6 & 4.07 & 22.2 & Agree \\
\hline $\begin{array}{l}\text { 4. My supervisor defends } \\
\text { my work actions to a } \\
\text { superior, even without } \\
\text { complete knowledge of the } \\
\text { issue in question }\end{array}$ & 5.3 & 5.8 & 21.0 & 34.2 & 33.7 & 3.85 & 28.9 & Agree \\
\hline $\begin{array}{l}\text { 5. My supervisor would } \\
\text { come to my defence if I } \\
\text { were "attacked" by others }\end{array}$ & 6.0 & 5.3 & 25.4 & 33.9 & 29.3 & 3.75 & 29.7 & Agree \\
\hline $\begin{array}{l}\text { 6. My supervisor would } \\
\text { defend me to others in the } \\
\text { organisation if I made an } \\
\text { honest mistake }\end{array}$ & 6.9 & 8.1 & 31.6 & 32.1 & 21.2 & 3.53 & 31.8 & Agree \\
\hline Loyalty & 6.1 & 6.4 & 26.0 & 33.4 & 28.1 & 3.71 & 27.6 & Agree \\
\hline $\begin{array}{l}\text { 7. I do work for my } \\
\text { supervisor that goes } \\
\text { beyond what is specified in } \\
\text { my work description }\end{array}$ & 3.5 & 11.3 & 17.3 & 37.2 & 30.7 & 3.80 & 28.9 & Agree \\
\hline $\begin{array}{l}\text { 8. I am willing to apply } \\
\text { extra efforts, beyond those } \\
\text { normally required, to } \\
\text { further the interests of my } \\
\text { work group }\end{array}$ & 2.5 & 3.9 & 11.5 & 41.8 & 40.2 & 4.13 & 22.8 & Agree \\
\hline $\begin{array}{l}\text { 9. I do not mind working } \\
\text { hardest for my supervisor }\end{array}$ & 2.3 & 5.3 & 15.7 & 39.7 & 37.0 & 4.04 & 24.1 & Agree \\
\hline Contribution & 2.8 & 6.9 & 14.9 & 39.6 & 36.0 & 3.99 & 20.4 & Agree \\
\hline $\begin{array}{l}\text { 10. I am impressed with } \\
\text { my supervisor's }\end{array}$ & 2.3 & 5.5 & 14.8 & 42.5 & 34.9 & 4.02 & 24.0 & Agree \\
\hline
\end{tabular}


International Journal of Computer Science \& Information Technology (IJCSIT) Vol 8, No 1, February 2016

\begin{tabular}{|c|c|c|c|c|c|c|c|c|}
\hline knowledge of his/ her job & & & & & & & & \\
\hline $\begin{array}{c}\text { 11. I respect my } \\
\text { supervisor's knowledge of } \\
\text { and competence on the job }\end{array}$ & 1.8 & 5.1 & 15.0 & 35.6 & 42.5 & 4.12 & 23.5 & Agree \\
\hline $\begin{array}{c}\text { 12. I admire my } \\
\text { supervisor's professional } \\
\text { skills }\end{array}$ & 1.8 & 6.2 & 18.9 & 34.9 & 38.1 & 4.01 & 24.8 & Agree \\
\hline $\begin{array}{c}\text { Professional respect } \\
\text { LMX }\end{array}$ & 2.0 & 5.6 & 16.2 & 37.6 & 38.5 & 3.74 & 25.2 & Agree \\
\hline & 5.9 & 18.0 & 36.5 & 36.0 & 3.88 & 19.7 & Agree \\
\hline
\end{tabular}

The information presented in this table indicates the extent to which the participant's agree with LMX quality. Statement (No.1), namely "I like my supervisor very much as a person", was the only statement that demonstrated a "strongly agree attitude" with a weighted mean of 4.29. The rest of the statements generated weighted mean values of between 4.13 and 3.53, which implies that the participants largely concurred with each statement. They alsostrongly agreedwith the total factors "LMX-Affect, LMX-Loyalty, LMX- Contribution and LMX- Professional Respect" as they generated weighted mean values of 4.07, 3.71, 3.99 and 3.74 respectively. The participants strongly agreedwith the total factor "LMX" as it has a total weighted mean value of 3.88 . The generation of high values in relation to this scale reflect employee-manager relationships that are characterised by a great degree of affect, loyalty, contribution and professional respect.

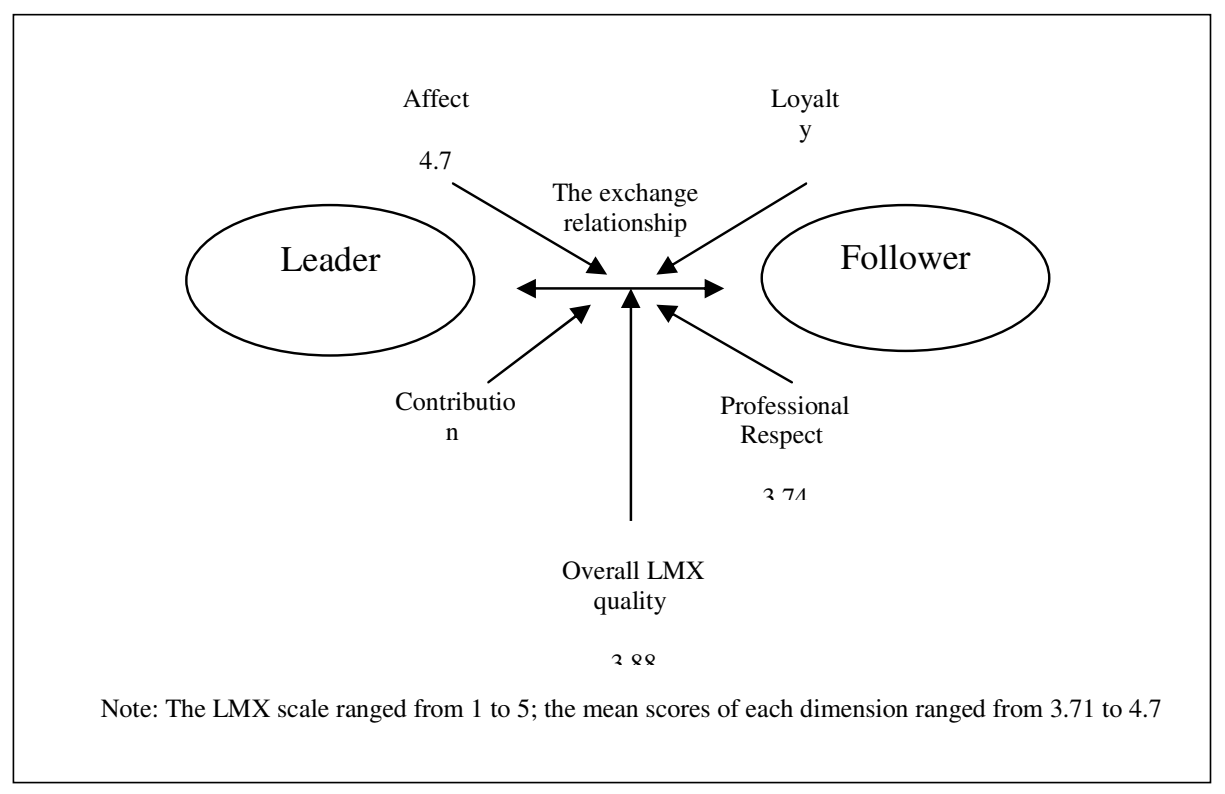

Figure 2: Mean scores of LMX dimensions based on employee perspectives at KAU

As illustrated in the diagram above, LMX in KAU in Saudi Arabia is characterised by scores whose mean ranged from 3.71 to 4.7. These scores indicate a strong level of agreement among the employees at KAU in regard to LMX quality (mean score=3.88). Significant findings have been discovered in relation to high LMX mean scores by earlier scholars who performed tests in culturally-analogous and culturally-diverse societies. For instance, studies were performed in 
collectivistic societies such as Turkey where a 5.27 LMX mean score was reported in a study by Pellegrini and Scandura (2006) and a 4.86 LMX mean score was reported in India (Pellegrini et al, 2010). Pellegrini and colleagues used the seven-point scale of LMX, which is equivalent to the five-point scale applied in the present study (see appendix C; this will be discussed in more detail in section 7). A 5-point scale has also been applied in different collectivist societies. For instance,in a Chinese context, LMX ranked highly with followers as a mean score of 4.32, 4.80 and 3.81 was achievedby Chan and $\operatorname{Mak}(2011)$, Li et al. (2010) and Wang et al.(2005) respectively. All these scores reflect the "agree" and "strongly agree" categories of LMX quality based on a 5-point scale response (see appendix D). In addition, in a Malaysian context, LMX had a reported mean of 3.84 in a study by Bakar, Dilbeck\&McCrosky (2010) which indicates the "agree" and "strongly agree" categories of LMX quality using a 5-point scale. Thus, the results generated by the present study support those of previous studies performed in collectivist cultures.

In terms of individualistic cultures, LMXobtained high scores from followers. For example, in the United States, LMX was ranked highly in a 7-point response scale as mean scores of 5.80 were achieved by O'Donnell et al.(2012) and 5.19 by Pellegrini et al.(2010), scores that are equivalent to the "agree" category of LMX quality (see appendix C). Moreover, LMX reported a high mean score of 4.48 in the Netherlands (Van Dam et al., 2008); similarly, a longitudinal study performed by Volmer, Niessen, Spurk, Linz and Abele (2011) on LMX reported high mean scores of 3.38 and 3.42 at time 1 and time 2 respectively, which suggests that the employees strongly agreedwith LMX quality. The findings generated by the present study serve to validate LMX as a cross-cultural construction and this alone contributes a significant amount to the existing field of knowledge.

\section{DISCUSSION}

While most LMX research studies have been performed onan individual basis (Schriesheim, Castro, Zhou \&Yammarino, 2001), the present study obtained data by eliciting employee perceptions on the relationship that is forged between them and their superiors. The subsequent findings imply that LMX quality is ranked highly by KAU employees and their managers, a conclusion that has been reached following the application of statistical analysis, factor analysis and ranking analysis using a Likert-type scale.

Factor analysis confirmed that LMX quality is a multidimensional construct in the KAU workplace that is based on four dimensions, namely affect, loyalty, contribution and professional respect. This supports the findings of other reported studies (e.g. Liden\&Maslyn, 1998; Maslyn\&Uhl-Bien, 2001; Bhal et al., 2009; Schyns et al., 2005; Lee, 2005; Wang et al., 2005; Schyns\& Wolfram, 2008; Greguras\& Ford,2006; Lee \& Wei, 2008).

Furthermore, the Likert-type scale generated ranking analysis results which indicate that the LMX concept is relevant to the employees at KAU (mean=3.88). This scale asked respondents to demonstrate the extent to which they agreed with the given statement with 1 meaning "strongly disagree" and 5 meaning "strongly agree". The weighted mean value calculated falls within the "agree" category, which represents a positive result as indicated by the agreement level table (see table 5, see figure 2). Thus, the present study concludes that LMX is highly ranked by the respondents and their managers. To validate the high LMX scores generated, the mean score of LMX quality was cross-checked with the scores generated by Pellegrini and Scandura's (2006) study as both are performed in a Middle Eastern context where respondents are likely to share common cultural and religious beliefs. Pellegrini and Scandura (2006) analysed LMX quality in five separate Turkish firms. A seven-point response scale was given for each survey item and 
higher scores were indicative of higher exchange quality; the mean score generated in this case was 5.27.

The response scale format (1-7) for the Likert-type scale adopted by Pellegrini and Scandura (2006) is the same as the response rate format used in the present study (1-5). According to Dawes (2008), statistical analysis indicates that five- and seven-point scales generated comparable mean scores when they were re-scaled (see appendix C). Thus, the LMX mean score achieved in the present study reflect those generated by Pellegrini and Scandura (2006) as the mean scores in each case are equivalent to the "agree" category. Accordingly, both studies demonstrate high LMX quality. The similarity of these results may be attributable to the fact that Turkey and Saudi Arabia are both Middle Eastern countries that most likely share the same cultural ideals on account of the common Islamic and collectivistic values of these countries. This viewpoint is based primarily on the Muslim ideology which regards the entire Islamic community as a brotherhood (Pellegrini\&Scandura, 2006) in which robust interpersonal relationships are the cultural norm.

Saudi Arabia is a collectivist society that places significant emphasison personal and societal relationships (Al-Gahtani, Hubona\& Wang, 2007). The findings of the present study substantiate those ofprevious studies that were performed in collectivistic communities beyond the Middle Eastern region. For example, LMX quality has also been found to be high in India (Pellegrini et al., 2010), China (Chan and Mak,2011, Li et al., 2010, Wang et al., 2005) and Malaysia(Bakar, Dilbeck\&McCrosky, 2010).

Cultural factors encourage people in these communities to classify people into in-groups and outgroups (particularism) (Hofstede, 1984). In-group members are more likely to establish strong working relationships with leaders and may benefit from more rewards than those in the outgroup (Graen, Wakabayashi, Graen\&Graen, 1990; Liden\&Maslyn, 1998). As stated by Hofstede (2001), those living in collectivistic societies are classified into robust in-groups that offer support and protection in exchange for loyalty (Hofstede, 2001). Broadly speaking, in-group collectivism places emphasis on how much pride and loyalty a member conveys toward their social group (Waldman, Luque, Washburn \& House, 2006). Consequently, the present research study classifies the surveyed employees from KAU as "in-group" members.

The similarity between the findings of the present study and previous research studies may be attributable to the Similarity-Attraction Paradigm or the overall tendency for cultures to behave cohesively (Testa, 2009). Thus, the nature and extent of employee-leader exchanges may be influenced by the prevailing values of the local culture.

Thus, we should perhaps explore how national cultures affect the relationship that is forged between leaders and followers.It is clear that the national culture plays a key role in workplace dynamics as employees share the same beliefs, ideas and attitudes (Testa, 2009). For instance, a manager may subconsciously make an assumption about a follower simply because of their shared cultural heritage. It is also possible for leaders to notice more positive subordinate behaviours when they share similar cultural values to specific followers and may demonstrate favouritism toward theseemployees accordingly. This may arise from automatic categorisationand the prototypical behaviours of a "good" employee thatthe leader associates with followers who share similar cultural ideals.Testa (2009) states that employees assess the quality of their relationship with their managers more positively when the manager belongs to the same national culture. Therefore, managers may assume that they are less likely to experience problems with employees from the same cultural background (Lo et al., 2010). Clearly, this is an area that calls for further investigation. 
The findings also highlight the impact of length of service on LMX scores as $43.6 \%$ of employees who had worked for the university for five years or less made a significant contribution to the high LMX scores achieved within the entire sample group (high LMX in Saudi context; see table 4). These findings may indicate that newer employees value their relationships with immediate managers more highly because they aim to establish and maintain high LMX quality relationships with their superiors in the long-term future. This may also be true for Saudi employees who are keen to establish a rapport with their leader at the beginning of their career so that they gain access to all support and resources necessary to maintain forward progress in terms of professional development in a society where many Saudi workers depend on family or peer connections when attempting to achieve personal goals (Bierke\& Al-Meer, 1993; Osland et al., 2000; Al-Gahtani et al., 2007). Thus, newer employees must forge strong interpersonal relationships with their managers in order to gain the support and guidance required to perform their role effectively and develop their future career.

However, conflicting results were generated by George and Hancer (2005) who found that the LMX scores of employees with long-term tenure at US firms were significantly higher in comparison to employees who had only been hired within the last two years. This outcome may be attributable to cultural differences. For instance, employees in individualistic cultures such as theUS show less of an interest in becoming an "in group" member when they start a new job with a new firm. However, the strength of their relationship with their superiors is likely to improve naturally over time as they engage more frequently in work-related tasks. Nonetheless, further research is required on the cultural differences between other collectivistic societies in order to determine how job tenure affects LMX quality.

Analysis of LMX in a Saudi context has contributed toward the comprehensive network of LMX research and the present study provides valuable knowledge on the scope of LMX theory by investigating how effectively it can be applied in a collectivistic context. Firstly, high LMX quality in KAU demonstrates that cultural collectivist ideals can be considered prerequisites of positive social interactions in a workplace environment. In effect, high LMX quality in KAU demonstrates that Arab values in Gulf Cooperation Council (GCC) countries, like the notion of brotherhood for example, may be conducive to the cultivation of good LMX as indicated by the high LMX scores given by KAU employees. Secondly, this study offers insights into the crosscultural application of LMX theory by examining LMX from a Saudi perspective. Thus, future research studies can compare results with those generated by the present study in a Saudi context. To this end, the researcher recommends that future studies perform a comparative cross-cultural analysis of LMX in terms of content (the dimensions of the exchange) as well as the manner in which it develops. The high LMX scores obtained in KAU implies the importance of a more refined approach in investigating the impact of culture on LMX. In addition, analysis of the cross-cultural reciprocity process could perhaps be the focus of future studies (e.g., Uhl-Bien \&Maslyn, 2003) so that we can obtain more knowledge on the fundamental impact of cultural factors on LMX.

\section{CONCLusion}

This study has contributed toward the existing field of knowledge on the translation of research instruments by applying a specific translation and adaptation procedure in formulating an Arabic version of the Leader-Member Exchange (LMX). The translated version was then used in a Saudi work environment where 433 employees at King Abdul-Aziz University (KAU) in Saudi Arabia, Jeddah were invited to participate. This paper highlights the importance of using validated psychometric instruments that have been adequately tested as well as the value in implementing regimented processes in modifying instruments so that they can be applied to a diverse range of languages and cultures. 


\section{REFERENCES}

1. Al-Gahtani, S. S., Hubona, G. S., \& Wang, J. (2007). Information technology (IT) in Saudi Arabia:culture and the acceptance and use of IT. Information \& Management, 44, 681-691.

2. Bakar, H. A., Dilbeck, K. E., \&McCrosky, J. C. (2010). Mediating role of supervisory communication practices on relations between leader-member exchange and perceived employees commitment to workgroup, Communication Monographs, 77(4), pp.637-656.

3. Bass, B. M., \&Avolio, B. J. (1990).The implications of transactional and transformational leadership for individual, team, and organizational development.In R. W. Woodman \& R. Passmore (Eds.).Research in organizational change and development (Vol. 4, pp. 231-272). Greenwich: JAI Press.

4. Bell, J. (2005). Doing your research project: a guide for first-time researchers in education, health and social science. Maidenhead: Open University Press.

5. Bhal, K. T, Gulati, N., \& Ansari, M. A. (2009). Leader-member exchange and subordinate outcomes: test of a mediation model. Leadership and Organisational Development Journal, 30(2), 106-125.

6. Bierke, B.,\& Al-Meer, A. (1993). Culture's consequences: management in Saudi Arabia. Leadership and Organisation Development Journal, 14(2), 30-35.

7. Blau, P. (1964). Exchange and power in social life. New York: John Wiley.

8. Brislin, R. W. (1980). Translation and content analysis of oral and written materials. In H.C. Triandis and J.W. Berry (eds.), Handbook of cross-cultural psychology (Vol. 2, pp. 389-444). Boston: Allyn \& Bacon.

9. Brislin, R., Lonner, W. J., \& Thorndike, R. (1973).Cross-cultural research methods. New York, NY: Wiley.

10. Chan, S. C. H., \&Mak, W. (2011). Benevolent leadership and follower performance: the mediating role of leader-member exchange (LMX). Asia Pacific Journal of Management, 29, 285-301.

11. Cohen, J., \& Cohen, P. (1983).Applied multiple regression/correlations analysis for the behavioral sciences. Hillsdale, NJ: Erlbaum.

12. Cronbach, L. J. (1984). Essentials of psychological testing.New York; London, Harper \& Row.

13. Dansereau, F., Graen, G., \&Haga, W. (1975).A vertical dyad linkage approach to leadership within formal organizations - a longitudinal investigation of the role making process. Organizational Behavior and Human Performance, 13, 46-78.

14. Dawes, J. (2008). Do data characteristics change according to the number of scale points used? An experiment using 5-point, 7-point and 10-point scales.International Journal of Market Research, 50(1), 61-77.

15. Dienesch, R., \&Liden, R. (1986). Leader-member exchange model of leadership: a critique and further development. Academy of Management Review, 11, 618-634.

16. Dulebohn, J., Bommer, W. H., Liden, R. C., Brouer, R. L., \& Ferris, G. R. (2011). A meta-analysis of antecedents and consequences of leader-member exchange: integrating the past with an eye toward the future. Journal of Management, 10(10), 1-45.

17. Field, A. (2009). Discovering statistics using SPSS ( $3^{\text {th }}$ Ed). Los Angeles: SAGE.

18. George, R. T., \&Hancer, M. (2005). Leader-member exchange quality: an empirical investigation in restaurants. Journal of Human Resources in Hospitality and Tourism, 3(2), 85-99.

19. Gerstner, C. R., \& Day, D. V. (1997). Meta-analytic review of leader-member exchange theory: correlates and construct issues. Journal of Applied Psychology, 82(6), 827-844.

20. Gomez, C., \& Rosen, B. (2001).The leader-member exchangeas a link between managerialtrust and employee empowerment.Group and Organization Management, 26, 1, 53-69.

21. Graen, G. B. (1976). Role making processes within complex organizations. In M. D. Dunnette (Ed.), Handbook of industrial and organizational psychology (pp. 1201-1245). Chicago, IL: Rand McNally.

22. Graen, G. B., \&Scandura, T. A. (1987).Toward a psychology of dyadic organizing.Research in Organizational Behaviour, 9, 175-208.

23. Graen, G. B., \&Scandura, T. A. (1987).Toward a psychology of dyadic organizing.Research in Organizational Behaviour, 9, 175-208.

24. Graen, G. B., \&Uhl-Bien, M. (1991). The transformation of professionals into self-managing and partially self-designing contribution: towards a theory of leadership making. Journal of Management Systems, 3(3), 33-48.

25. Graen, G. B., \&Uhl-Bien, M. (1991). The transformation of professionals into self-managing and partially self-designing contribution: towards a theory of leadership making. Journal of Management Systems, 3(3), 33-48. 
26. Graen, G. B., \&Uhl-Bien, M. (1995). Relationship-based approach to leadership: development of leader-member exchange (LMX) theory of leadership over 25 years: applying a multi-level multidomain perspective. Leadership Quarterly, 6, 219-247.

27. Graen, G. B., \&Uhl-Bien, M. (1995). Relationship-based approach to leadership: development of leader-member exchange (LMX) theory of leadership over 25 years: applying a multi-level multidomain perspective. Leadership Quarterly, 6, 219-247.

28. Graen, G. B., \&Uhl-Bien, M. (1995). Relationship-based approach to leadership: development of leader-member exchange (LMX) theory of leadership over 25 years: applying a multi-level multidomain perspective. Leadership Quarterly, 6, 219-247.

29. Graen, G. B., Wakabayashi, M., Graen, M. R., \&Graen, M. G. (1990). International generalizability of American hypotheses about Japanese management progress: a strong inference investigation. Leadership Quarterly, 1, 1-23.

30. Graen, G., \& Cashman, J. (1975). A role making model of leadership in formal organizations: a developmental approach. In J. Hunt \& L. Larson (Eds.), Leadership frontiers (pp143-165). Kent OH: Kent State University Press.

31. Greguras, G. J., \& Ford, J. M. (2006).An examination of the multidimensionality of supervisor and subordinate perceptions of leader-member exchange.Journal of Occupational and Organizational Psychology, 79, 433-465.

32. Hackman, J. R., \&Wageman, R. (2005). When and how team leaders matter.Research in Organizational Behaviour, 26, 37-74.

33. Hair, J. F, Anderson, R.E., Tatham, R.C, Black, W.C (1998), Multivariate Data Analysis, PrenticeHall, Upper Saddle River, NJ.

34. Hair, J., Tatham, R., \& Anderson, R. (2002).Multivariate data analysis. London: Prentice Hall PTR.

35. Harter, N., \&Evanecky, D. (2002). Fairness in leader-member exchange theory: do we all belong on the inside? Kravis Leadership Institute Leadership Review [Electronic version]. Retrieved-onSeptember-24,-2012-formhttp://www.leadershipreview.org/2002summer/article1_summer_2002.asp

36. Hofstede, G. (1984). Culture's consequences: international differences in work-related values. Beverly Hills, CA: Sage.

37. Hofstede, G. (2001). Cultures consequences: Comparing values, behaviours, institutions and organizations across nations $\left(2^{\text {nd }}\right.$ Ed.). Thousand Oaks, CA: Sage.

38. Hollander, E. P. (1992a).The essential interdependence of leadership and followership.Current Directions in Psychological Science, 1, 71-75.

39. Hollander, E. P. (1992b).Leadership, followership, self, and others.Leadership Quarterly, 3, 43-54.

40. Ilies, R., Nahrgang, J. D., \&Morgeson, F. P. (2007). Leader-member exchange and citizenship behaviors: a meta-analysis. Journal of Applied Psychology, 92(1), 269-277.

41. Joreskog, K. G., \&Sorbom, D. (1989). Lisrel.A guide to program and applications. Chicago: SPSS, Inc.

42. Katz, D., \& Kahn, R. L (1978).The social psychology of organisations (2 ${ }^{\text {nd }}$ Ed). New York: John Wiley.

43. Lee, J. (2005). Effects of leadership and leader-member exchange on commitment. Leadership and Organization Development Journal, 26, 655-672.

44. Lee, J., \& Wei, F. (2008). Uncover the black box of leadership effectiveness: leader-member exchange as the mediator. Frontiers of Business Research in China, 2, 240-255.

45. Li, N., Liang, J., \&Crant, J. M. (2010). The role of proactive personality in job satisfaction and organizational citizenship behaviour: a relational perspective. Journal of Applied Psychology, 95(2), 395- 404.

46. Liden, R. C., \&Maslyn, J. M. (1998). Multidimensionality of leader-member exchange: an empirical assessment through scale development. Journal of Management, 24(1), 43-73.

47. Liden, R. C., Wayne, S. J., \& Stilwell, D. (1993). A longitudinal study on the early development of leader-member exchange. Journal of Applied Psychology, 78, 662-674.

48. Lo, M. C., Ramayah, T., Min, H. W., \&Songan, P. (2010). The relationship between leadership styles and organizational commitment in Malaysia: role of leader-member exchange. Asia Pacific Business Review, 16(1/2),79-103.

49. Maslyn, J., \&Uhl-Bien, M. (2001). Leader-member exchange and its dimensions: effects of self-effort and other's effort on relationship quality. Journal of Applied Psychology, $\quad 86,697-708$.

50. Northouse, P. (2007). Leadership: theory and practice $\left(4^{\text {th }}\right.$ Ed). London: Sage Publications.

51. Nunnally, J. C. \& Bernstein, I. H. (1994).Psychometric theory ( $3^{\text {rd }}$ Ed.). New York: McGraw Hill.

52. Nunnally, J. C. \& Bernstein, I. H. (1994).Psychometric theory ( $3^{\text {rd }}$ Ed.). New York: McGraw Hill. 
53. O’Donnell, M., Yukl, G., \& Taber, T. (2012). Leader behavior and LMX: a constructive replication. Journal of Managerial Psychology, 27(2), 143-154.

54. Osland, J. S., Bird, A., Delano, J., \& Jacob, M. (2000).Beyond sophisticated stereotyping: cultural sense making in context.The Academy of Management Executive, 14, 65-80.

55. Pellegrini, E. K., \&Scandura, T. A. (2006). Leader member exchange (LMX), paternalism and delegation in the Turkish business culture: an empirical investigation. Journal of International Business Studies, 37(2), 264-279.

56. Pellegrini, E. K., Scandura, T. A., \&Jayaraman, V. (2010). Cross-cultural generalizability of paternalistic leadership: an expansion of leader-member exchange theory. Group and Organization Management, 35(4) 391-420.

57. Popper, M. (2004).Leadership as relationship. Journal for the Theory of Social Behaviour, 34, 107125.

58. Scandura, T. A. (1999). Rethinking leader-member exchange: an organisational justice perspective.Leadership Quarterly, 10(1), 25-40.

59. Schriesheim, C. A., Castro, S. L., Zhou, T., \&Yammarino, F. J. (2001). The folly of theorizing "A” but testing "B".A selective level-of-analysis review of the field and a detailed leader-member exchange illustration.The Leadership Quarterly, 12,515-551.

60. Schyns, B., \& Wolfram, H.-J. (2008). The relationship between leader-member exchange and outcomes as rated by leaders and followers. Leadership and Organization Development Journal, 29(7), 631-646.

61. Schyns, B., Paul, T., Mohr, G., \& Blank, H. (2005).Comparing antecedents and consequences of leader-member exchange in a German working context to findings in the US.European Journal of Work and Organizational Psychology, 14(1), 1-22.

62. Sparrowe, R. T., Liden, R. C., Wayne, S. J., \&Kraimer, M. L. (2001).Social networks and the performance of individuals and groups.Academy of Management Journal, 44, 316-325.

63. Tabachnick, B. G., \&Fidell, L. S. (2007).Using multivariate statistics $\left(5^{\text {th }}\right.$ Ed). Boston, MA: Pearsons Education Inc.

64. Testa, M. R. (2009). National culture, leadership and citizenship: implications for cross-cultural management. International Journal of Hospitality Management, 28(1), 78-85.

65. Truckenbrodt, Y. B. (2000). An empirical assessment of the relationship between leader-member exchange and organizational commitment and organizational citizenship behavior.Unpublished doctoral dissertation, Nova Southeastern University, Ft. Lauderdale, FL.

66. Tsui, A. S., Ashford, S. J., St. Clair, L., \& Xin, K. R. (1995). Dealing with discrepant expectations: response strategies and managerial effectiveness? Academy of Management Journal, 38(6), 1515-1543.

67. Uhl-Bien, M., \&Maslyn, J. M. (2003). Reciprocity in manager-subordinate relationships: components, configurations, and outcomes. Journal of Management, 29(4) 511-532.

68. Uhl-Bien, M., Maslyn, J., \&Ospina, S. (2012). The nature of relational leadership: a multi-theoretical lens on leadership relationships and process. In D. V. Day \& J. Antonakis (Eds).The nature of leadership ( $2^{\text {nd }}$ Ed) (pp. 289-330). London: SAGE Publications.

69. Van Dam, K., Oreg, S., \&Schyns, B. (2008). Daily work contexts and resistance to organisational change: the role of leader-member exchange, development climate, and change process characteristics. Applied Psychology, 57(2), 313-334.

70. Volmer, J., Niessen,C., Spurk,D., Linz, A., \& Abele, A. E. (2011). Reciprocal Relationships between Leader-Member Exchange (LMX) and Job Satisfaction: A Cross-Lagged Analysis, Applied Psychology: An International Review, 0(0), 1-24. DOI: 10.1111/j.1464-0597.2011.00446.x

71. Waldman, D. A., Luque, M. S., Washburn, N., \& House, R. J. (2006). Cultural and leadership predictors of corporate social responsibility values of top management: a globe study of 15 countries. Journal of International Business Studies, 37, 823-837.

72. Wang, H., Law, K. S., Hackett, R. D., Wang, D., \& Chen, Z. X. (2005).Leader-member exchange as a mediator of the relationship between transformational leadership and followers' performance and organisational citizenship behaviour.Academy of Management Journal, 48(3), 420-432.

73. Wayne, S. J., Shore, L. M., \&Liden, R. C. (1997). Perceived organizational support and leadermember exchange: A social exchange perspective. Academy of Management Journal, 40, 82-111.

74. Yukl, G. (2008). How leaders influence organizational effectiveness.The Leadership Quarterly, 19, 708-722.

75. Yukl, G. (2010). Leadership in organizations ( $7^{\text {th }}$ Ed.). Upper Saddle River, NJ: Pearson Education. 
International Journal of Computer Science \& Information Technology (IJCSIT) Vol 8, No 1, February 2016

\section{AUTHORS}

Dr.NahlaAljojo earned a $\mathrm{PhD}$ in Computing at Portsmouth University, UK. She is work as assistant professor at Faculty of Computing and Information Technology - Information System Department- King Abdulaziz University, Jeddah, Saudi Arabia. Her research interests include adaptivity in Web based educational systems, E-business, Leaderships studies and information security.

Dr.AreejAlshamasi earned a PhD in Business school at Portsmouth University, UK. She is work as assistant professor at Faculty of Economics and Administration - public AdministrationDepartment- King Abdulaziz University, Jeddah, Saudi Arabia. Her research interests include in Leaderships studies and Human resources. 